\title{
Incidence of rhinitis and asthma related to welding in Northern Europe
}

\author{
Torgeir Storaas ${ }^{1,2}$, Jan-Paul Zock ${ }^{3}$, Ana Espinosa Morano ${ }^{3}$, Mathias Holm ${ }^{4}$, \\ Eythor Bjørnsson ${ }^{5}$, Bertil Forsberg ${ }^{6}$, Thorarinn Gislason ${ }^{7,8}$, Christer Janson ${ }^{9}$, \\ Dan Norback ${ }^{10}$, Ernst Omenaas ${ }^{11}$, Vivi Schlünssen ${ }^{12}$, Kjell Torén ${ }^{4}$ and \\ Cecilie Svanes ${ }^{1,13}$
}

\begin{abstract}
Affiliations: ${ }^{1}$ Dept of Occupational Medicine, Haukeland University Hospital, Bergen, Norway. ${ }^{2}$ Dept of Otolaryngology, Head and Neck Surgery, Haukeland University Hospital, Bergen, Norway. ${ }^{3}$ Centre for Research in Environmental Epidemiology (CREAL), Barcelona, Spain. ${ }^{4}$ Occupational and Environmental Medicine, Sahlgrenska University Hospital, Gothenburg. Sweden. ${ }^{5}$ Dept of Respiratory Medicine and Sleep, Landspitali-University Hospital, Reykjavik, Iceland. ${ }^{6}$ Dept of Public Health and Clinical Medicine, Occupational and Environmental Medicine, Umeå University, Umeå, Sweden. ${ }^{7}$ Faculty of Medicine, University of Iceland, Reykjavik, Iceland. ${ }^{8}$ Dept of Respiratory Medicine and Sleep, Landspitali, National University Hospital of Iceland, Reykjavik, Iceland. ${ }^{9}$ Dept of Medical Sciences: Respiratory Medicine and Allergology, Uppsala University, Uppsala, Sweden. ${ }^{10}$ Dept of medical Science, Occupational and Environmental Medicine, Uppsala University, Uppsala, Sweden. ${ }^{11}$ Centre for Clinical Research, Haukeland University Hospital, Bergen, Norway. ${ }^{12}$ Section for Environment, Occupation and Health, Department of Public Health, Aarhus University, Aarhus, Denmark. ${ }^{13}$ Centre for International Health, University of Bergen, Bergen, Norway.
\end{abstract}

Correspondence: Torgeir Storaas, Department of Occupational Medicine, Haukeland University Hospital, 5021 Bergen, Norway. E-mail: torgeir.storaasahelse-bergen.no

ABSTRACT Welding-related asthma is well recognised but less is known about rhinitis in relation to welding. The aim here, was to study associations between welding, rhinitis and asthma in a general population sample, and factors influencing selection into and out of a welding occupation.

Adult-onset asthma and non-infectious rhinitis were investigated in the international multicentre population-based Respiratory Health in Northern Europe (RHINE) study, including 16191 responders aged $26-54$ years. Ever welding $(n=2181)$, welding $>25 \%$ of working time $(n=747)$, and welding in stainless steel $>6$ months $(n=173)$ were assessed by questionnaire. Subjects with rhinitis or asthma onset when aged $<18$ years were excluded. Incidence rates for asthma and rhinitis were calculated from year of disease onset, and start and end of welding job. Cox's proportional hazard models adjusting for age, sex, parental education and study centre, and Kaplan-Meier curves were used.

Rhinitis incidence was higher among welders (hazard ratio (HR) 1.4, 95\% CI 1.3-1.6), consistent in men and women, and across centres (pheterogeneity=0.4). In men, asthma incidence was higher among welders (HR 1.4, 95\% CI 1.04-1.97). Quitting welding was indicated higher after adult-onset rhinitis (HR 1.1, 95\% CI 1.0-1.3).

Adult-onset rhinitis and asthma was higher among welders, consistent across population samples from Northern Europe. No pre-employment selection was found, whereas selection out of welding jobs was suggested.

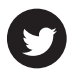

@ERSpublications

Welding activity increases risk of development of rhinitis, highlighting concerns in this occupation http://ow.ly/Owdqp

Received: Dec 222014 | Accepted after revision: May 142015 | First published online: July 232015

Support statement: This study received financial support from the Icelandic Research Council, the Swedish Heart and Lung Foundation, the Vårdal Foundation for Health Care and Allergic Research, the Swedish Association Against Asthma and Allergy, the Swedish Council for Working Life and Social Research, the Bror Hjerpstedt Foundation, the Norwegian Research Council project 135773/330, the Norwegian Asthma and Allergy Association, The Danish Lung Association and the Estonian Science Foundation, grant 4350. Funding information for this article has been deposited with FundRef.

Conflict of interest: None declared.

Copyright OERS 2015 


\section{Introduction}

Welding-related exposures have been related to a variety of health problems. Workplace exposure to welding fumes has been linked to lung function impairment, obstructive and restrictive lung disease, cough, dyspnoea, rhinitis, metal fume fever, asthma, pneumonitis, pneumoconiosis, carcinoma of the lungs and also to neurological symptoms, chronic renal failure, eye irritation, photo keratitis, cataract, skin irritation, erythema, pterygium, non-melanocytic skin cancer, malignant melanoma, reduced sperm count and motility, and infertility [1-3].

Recently we have shown an association between welding and new-onset chronic bronchitis symptoms [4]. Welding as a cause of asthma has been subject of debate. A recently published large population based study based on a 9-year follow up of the first European Community Respiratory Health Survey (ECRHS) did not show any overall association between welding and asthma or asthma symptoms. Nevertheless, wheeze was related to welding in painted metal [5]. In contrast, the Shield surveillance programme showed that welders accounted for $9 \%$ of reported occupational asthma cases in the period 1990-2004 [6]. In Michigan (USA), they found in a follow-up of a state-wide surveillance that welding exposure was a common cause of work-related asthma resulting in high morbidity and health care costs [7].

Few papers have addressed the upper airways in relation to welding. In a clinical study on occupational asthma due to welding fumes from stainless steel, it was found that in addition to respiratory symptoms, $21(62 \%)$ patients also had nasal or laryngeal symptoms related to welding fumes [8]. A questionnaire study among 351 welders showed that $40.5 \%$ of the respondents had at least one nasal symptom related to welding [1]. In a population-based study of non-infectious rhinitis in relation to occupational exposure, $>30 \%$ of the respondents stated exposure to welding fumes but there was no significant association between welding and non-infectious rhinitis [9].

The Respiratory Health in Northern Europe (RHINE) cohort study is a large population-based study and, in 1999-2001, the postal questionnaire was supplemented with questions on welding. In this study, we investigated associations between adult-onset asthma, adult-onset non-infectious rhinitis and exposure to welding fumes in the general population. We also evaluated potential health-related selection factors into and out of occupations involving welding.

\section{Methods}

Study design and population

RHINE (www.rhine.nu) is a follow up study of adults from seven Northern European centres who participated in ECRHS stage 1, a study that took place in 1990-1994. In stage 1 of the ECRHS, men and women in the ages 20-44 years were randomly selected from the population registers from each participating centre. A postal questionnaire was sent to 3000-4000 persons in each centre. The target population for the RHINE study was the responders from Reykjavik in Iceland, Bergen in Norway, Umeå, Uppsala and Gothenburg in Sweden, Aarhus in Denmark and Tartu in Estonia ( $n=21802$; response rate 83.7\%). These subjects (excluding 264 who died) were sent a postal questionnaire in 1999-2001. Persons not responding to the first mailing were sent two reminders. In total, 16190 persons answered the questionnaire (response rate 75\%). The study was approved by the local ethics committees.

The present paper is based on longitudinal survival analysis of retrospectively recorded data on age of onset of asthma and rhinitis, and year of starting and quitting welding activity.

\section{Definition of new-onset asthma and rhinitis}

The first part of the questionnaire contained 12 questions that were identical with those asked in the ECRHS stage 1 [10]. These items covered respiratory symptoms during the last 12 months, current asthma medication and current hay fever. In the follow-up questionnaire more details of the outcomes asthma and rhinitis were added, including whether the participants had ever had asthma. Those answering "yes" were asked to state age of asthma onset. Adult-onset asthma was defined as asthma that started after age 18 years. Non-infectious rhinitis was defined as "ever having had nasal symptoms such as nasal blockage and secretion in the absence of common cold". Those answering "yes" were asked to state age of rhinitis onset. Adult-onset rhinitis was defined as non-infectious rhinitis starting after age 18 years.

We also analysed whether the duration of exposure to welding fumes had any impact on the likelihood of retracting rhinitis or asthma.

\section{Exposure assessment}

"Ever welding" was defined based on the question "Have you worked with welding or in any other way in your work been exposed to metal fumes/welding fumes?" Those answering "yes" were asked which year they started and quit those jobs (defining years of welding). They were also asked whether they had ever in 
any occupation been welding for $>25 \%$ of the working day and whether they altogether had been welding in stainless steel for $>6$ months. These questions defined welding $>25 \%$ of the working time, welding in stainless steel or not, and number of years with welding activity.

\section{Statistical analyses}

The STATA statistical package (version 11; StataCorp, College Station, TX, USA) was used for data analysis.

Possible pre-employment selection factors, such as childhood rhinitis and/or asthma, and educational level of parents, for working with welding after the age of 18 years, and welding for $>8$ years, were explored by using unconditional multiple logistic regression models, adjusting for age, sex and centre, and expressed as prevalence odds ratios with $95 \%$ confidence intervals.

Based on information about the year of starting welding, and the age when nose or asthma symptoms started, exposed and non-exposed person-years were calculated and analysis of incidence rates was performed for exposed and unexposed respectively. Survival analysis was used for the calculation of hazard ratios for rhinitis and asthma. The analysis started at the age of 18 or the year of welding onset and each respondent was followed until rhinitis (or asthma) occurred (both in exposed and non-exposed), or for those who did not develop rhinitis (or asthma), until the end of follow-up (the year of investigation, 1999, 2000 or 2001). Those with reported rhinitis (or asthma) prior to 18 years of age and those with reported rhinitis (or asthma) onset after the age of 18 years but prior to starting welding were excluded from the analysis.

For the univariate analysis, survival curves were estimated using the Kaplan-Meier method and log-rank tests were used to compare survival distributions for exposed and non-exposed groups. We performed crude and multivariate Cox proportional hazard models to assess the risk of first-ever asthma or rhinitis for exposed individuals in relation to non-exposed. In the multivariate models we adjusted for sex, smoking (never or ever) and parental education; all analyses were adjusted for centre. We used Schoenfeld residuals to verify the proportionality assumption. Separate analysis by centre and further meta-analyses were performed. We tested heterogeneity between effect estimates using a Q-statistic (Cochran Q-test) and $\mathrm{I}^{2}$. As no heterogeneity was found across centres, we used fixed-effect models.

\section{Results}

Having worked with welding or having been exposed to metal/welding fumes at work was reported by 2192 persons or $13.8 \%$ among subjects with available data on welding (table 1). Welding was more prevalent in Gothenburg and Umeå, most welders were male and smoking was more common among welders (table 1).

Table 2 shows incidence rates of adult-onset rhinitis and asthma according to welding exposures, in all participants and in men and women separately. Incidence rates for adult-onset rhinitis were uniformly and significantly higher in all exposed groups compared with never-welders, with incidence rate for rhinitis of 20.3 cases per 1000 years among welders and a significant HR of 1.4 (95\% CI 1.3-1.6). Significantly increased incidence of rhinitis was found in both male and female welders (table 2). Meta-analysis by study centre (fig. 1) showed consistently higher incidence rate of rhinitis among welders across Northern Europe (pheterogeneity=0.4).

The risk of adult-onset asthma associated with welding was significantly higher in men, with a HR of 1.4 (95\% CI 1.04-1.97; $\mathrm{p}=0.030$ ) (table 2). Incidence rates were particularly high for those who had welded $>25 \%$ of their working time and those having welded in stainless steel. Among the 219 women reporting ever having welded, asthma was reported only by seven; the asthma incidence in these female welders appeared to be non-significantly lower than among non-exposed women. Meta-analysis of hazard ratio for adult-onset asthma in relation to welding in men is presented in figure 2; data from Tartu were excluded due to small numbers. No heterogeneity between centres was found (pheterogeneity=0.9); the overall association reached statistical significance.

\section{Selection into and out of work with welding}

Persons with childhood-onset asthma non-significantly less often work as a welder (table 3). Neither early-onset rhinitis nor adolescent-onset asthma was associated with subsequent work with welding (table 3). Altogether; the proportion choosing to be a welder did not differ between those with and without childhood or adolescence rhinitis/asthma, but welding was significantly less common in those with a mother or father with higher education (table 3).

Incidence rates of rhinitis and of asthma appeared to be lower in those who had worked longer as welder (table 2, comparing having worked with welding $\leqslant 8$ versus $>8$ years). Continuing working as a welder was slightly less common among those with ever-rhinitis, expressed as a lower "survival" as welder in 


\begin{tabular}{|c|c|c|c|c|}
\hline & Ever welded & Never welded & Total & p-value $\#$ \\
\hline Subjects & 2192 & 13630 & 15822 & \\
\hline \multicolumn{5}{|l|}{ Centre } \\
\hline Aarhus & 285 (13.0) & $2268(16.6)$ & $2553(16.1)$ & \multirow[t]{7}{*}{0.000} \\
\hline Reykjavik & 247 (11.3) & 1660 (12.2) & $1907(12.1)$ & \\
\hline Bergen & $263(12.0)$ & $2129(15.6)$ & $2392(15.1)$ & \\
\hline Gothenburg & 394 (18.0) & $1740(12.8)$ & 2134 (13.5) & \\
\hline Umeå & 465 (21.2) & $2133(15.6)$ & $2598(16.4)$ & \\
\hline Uppsala & $228(10.4)$ & 2304 (16.9) & $2532(16.0)$ & \\
\hline Tartu & $310(14.1)$ & $1396(10.2)$ & 1706 (10.8) & \\
\hline Female & $219(10.0)$ & 8179 (59.8) & 8398 (52.9) & 0.000 \\
\hline Age years & $40.0 \pm 7.0$ & $39.8 \pm 7.3$ & $39.8 \pm 7.3$ & 0.267 \\
\hline Missing & 2 & 2 & 4 & \\
\hline \multicolumn{5}{|l|}{ Smoking } \\
\hline Never smoker & 796 (36.9) & $6348(47.2)$ & 7144 (45.8) & \multirow[t]{4}{*}{0.000} \\
\hline Ex-smoker & $576(26.7)$ & 3343 (24.9) & $3919(25.1)$ & \\
\hline Smoker & 783 (36.3) & 3749 (27.9) & $4532(29.1)$ & \\
\hline Missing & 37 & 190 & 227 & \\
\hline \multicolumn{5}{|l|}{ Maternal education } \\
\hline Lower & $1396(65.8)$ & 8145 (61.1) & 9541 (61.8) & \multirow[t]{4}{*}{0.000} \\
\hline Middle & 585 (27.6) & 3716 (27.9) & $4301(27.8)$ & \\
\hline Higher & $142(6.7)$ & 1460 (11.0) & $1602(10.4)$ & \\
\hline Missing & 69 & 309 & 378 & \\
\hline \multicolumn{5}{|l|}{ Paternal education } \\
\hline Lower & $1200(56.8)$ & $6804(51.1)$ & 8004 (51.9) & \multirow[t]{4}{*}{0.000} \\
\hline Middle & 675 (31.9) & 4185 (31.5) & 4860 (31.5) & \\
\hline Higher & 239 (11.3) & $2314(17.4)$ & $2553(16.6)$ & \\
\hline Missing & 78 & 327 & 405 & \\
\hline \multicolumn{5}{|l|}{ Asthma" } \\
\hline Never asthma & $1980(91.4)$ & $12220(90.4)$ & $14200(90.5)$ & \multirow[t]{3}{*}{0.133} \\
\hline Adult-onset asthma & $187(8.6)$ & $1305(9.6)$ & $1492(9.5)$ & \\
\hline Missing & 25 & 105 & 130 & \\
\hline \multicolumn{5}{|l|}{ Rhinitis ${ }^{\pi}$} \\
\hline Never rhinitis & $1005(47.0)$ & $7010(52.6)$ & 8015 (51.8) & \multirow[t]{3}{*}{0.000} \\
\hline Adult-onset rhinitis & $1132(53.0)$ & $6320(47.4)$ & $7452(48.2)$ & \\
\hline Missing & 55 & 300 & 355 & \\
\hline \multicolumn{5}{|l|}{ Welding activities } \\
\hline \multicolumn{5}{|l|}{$\%$ of working time } \\
\hline$<25 \%$ & $1252(58.8)$ & & & \\
\hline$>25 \%$ & $877(41.2)$ & & & \\
\hline Missing & 63 & & & \\
\hline \multicolumn{5}{|l|}{ Stainless steel } \\
\hline Welded, but not in stainless steel & 1956 (91.9) & & & \\
\hline Welded in stainless steel $>6$ months & $173(8.1)$ & & & \\
\hline Missing & 63 & & & \\
\hline Years of welding & $9(1-39)$ & & & \\
\hline Missing & 368 & & & \\
\hline
\end{tabular}

Data are presented as $\mathrm{n}, \mathrm{n}(\%)$, mean $\pm \mathrm{SD}$, or median (range), unless otherwise stated. " : Chi-squared test was used for categorical variables and t-test was used for continuous variables; " ${ }^{\text {? }}$ subjects with asthma or rhinitis before the age of 18 were excluded.

Kaplan-Meier estimates of welding by year of follow-up (fig. 3c). This effect was borderline significant, with a hazard ratio for quitting welding of 1.1 (95\% CI 1.0-1.3), adjusted for sex, smoking, education and centre. Kaplan-Meier graphs generally indicated higher quitting rates (lower "survival" in welding occupation) by year of follow-up among those with asthma or rhinitis, ever or with adult onset, (fig. 3a-d). These differences did not reach statistical significance (i.e. for adult-onset asthma, HR was 1.2 (95\% CI 0.9-1.6).

\section{Discussion}

In a large multicentre population-based study, we found that adult-onset rhinitis was more common in those who had ever been welding at work compared to never-welders. An increased risk related to welding 
TABLE 2 Incidence rate (cases per 1000 person-years) and hazard ratios (HR) of adult-onset non-infectious rhinitis and adult-onset asthma related to welding, and stratified by sex

\begin{tabular}{|c|c|c|c|c|c|c|c|c|c|}
\hline & \multicolumn{3}{|c|}{ All participants } & \multicolumn{3}{|c|}{ Male } & \multicolumn{3}{|c|}{ Female } \\
\hline & Number $\#$ & $\begin{array}{l}\text { Incidence } \\
\text { rate }\end{array}$ & HR & Number & $\begin{array}{l}\text { Incidence } \\
\text { rate }\end{array}$ & HR & Number & $\begin{array}{l}\text { Incidence } \\
\text { rate }\end{array}$ & HR \\
\hline $\begin{array}{l}\text { Incident rhinitis subsequent } \\
\text { to welding debut } \mathbf{n}\end{array}$ & & 11203 & & & 5376 & & & 6112 & \\
\hline Never welded & 3279 & 16.8 & 1 (Reference) & 1158 & 14.5 & 1 (Reference) & 2121 & 18.3 & 1 (Reference) \\
\hline Ever welded & 405 & 20.3 & $1.4(1.3-1.6)$ & 367 & 19.5 & $1.4(1.2-1.5)$ & 38 & 33.8 & $1.9(1.4-2.6)$ \\
\hline Welded $<25 \%$ of working time & 230 & 21.3 & $1.5(1.3-1.7)$ & 206 & 20.3 & $1.4(1.2-1.6)$ & 24 & 35.9 & $1.9(1.3-2.9)$ \\
\hline Welded $>25 \%$ of working time & 171 & 18.9 & $1.4(1.2-1.6)$ & 158 & 18.4 & $1.3(1.1-1.6)$ & 13 & 28.6 & $1.8(1.0-3.0)$ \\
\hline Welded, but not in stainless steel & 364 & 20.0 & $1.4(1.3-1.6)$ & 332 & 19.3 & $1.4(1.2-1.5)$ & 32 & 34.2 & $1.9(1.4-2.7)$ \\
\hline Welded in stainless steel $>6$ months & 38 & 23.4 & $1.6(1.2-2.2)$ & 34 & 23.5 & $1.6(1.2-2.3)$ & 4 & 22.5 & $1.3(0.5-3.5)$ \\
\hline Welding activity $\leqslant 8$ years & 162 & 22.0 & $1.5(1.3-1.8)$ & 138 & 20.5 & $1.4(1.2-1.7)$ & 24 & 38.3 & $2.3(1.5-3.4)$ \\
\hline Welding activity $>8$ years & 222 & 18.8 & $1.3(1.2-1.5)$ & 213 & 18.7 & $1.3(1.2-1.6)$ & 9 & 22.0 & $1.2(0.6-2.2)$ \\
\hline $\begin{array}{l}\text { Incident asthma subsequent to } \\
\text { welding debut } \mathbf{n}\end{array}$ & & 14211 & & & 6683 & & & 7528 & \\
\hline Never welded & 583 & 2.1 & 1 (Reference) & 155 & 1.4 & 1 (Reference) & 428 & & \\
\hline Ever welded & 55 & 1.8 & $1.2(0.9-1.7)$ & 53 & 1.8 & $1.4(1.0-2.0)$ & 2 & & \\
\hline Welded $<25 \%$ of working time & 26 & 1.5 & $1.1(0.7-1.6)$ & 24 & 1.5 & $1.2(0.8-1.9)$ & 2 & & \\
\hline Welded $>25 \%$ of working time & 28 & 2.1 & $1.4(1.0-2.1)$ & 28 & 2.2 & $1.7(1.1-2.5)$ & 0 & & \\
\hline Welded, but not in stainless steel & 48 & 1.7 & $1.2(0.9-1.7)$ & 46 & 1.7 & $1.4(1.0-1.9)$ & 2 & & \\
\hline Welded in stainless steel $>6$ months & 7 & 2.8 & $1.8(0.8-3.7)$ & 7 & 3.1 & $2.3(1.1-4.9)$ & 0 & & \\
\hline Welding activity $\leqslant 8$ years & 24 & 2.0 & $1.4(0.9-2.1)$ & 23 & 2.1 & $1.7(1.1-2.6)$ & 1 & & \\
\hline Welding activity $>8$ years & 29 & 1.7 & $1.2(0.8-1.7)$ & 28 & 1.7 & $1.3(0.8-1.9)$ & 1 & & \\
\hline
\end{tabular}

was also found for adult-onset asthma among men. The findings were consistent across seven study centres. The findings of rhinitis and asthma with onset subsequent to occupational welding were based on longitudinal analyses, and suggested a causal relationship. The incidence rate was decreased in the subgroup who had been welding for $>8$ years; in addition, adult-onset rhinitis seems to predict earlier quitting of welding work, pointing to the possibility of a healthy worker survivor effect.

There are few population based studies on exposure to welding fumes and the outcomes rhinitis and/or asthma. As in the ECRHS-based study from 2008, our questionnaire accounted for the diversity of occupations in which welding is undertaken [5]. The population sample is quite large, near the double the size of the sample in another ECRHS-based study that investigated occupation and adult onset of rhinitis in the general population [11].

The cities of Umeå and Gothenburg have car and truck industry explaining the high prevalence of welders in these cities. Umeå Volvo Trucks is the largest private work place in the city, which also has two factories producing front loaders and forest harvesters.

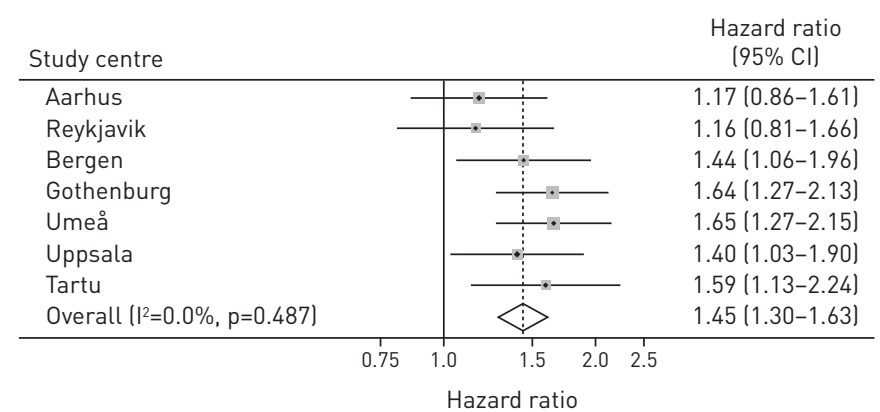

FIGURE 1 Hazard ratios for the association of welding with incident rhinitis by study centre. For each centre, the square gives the HR and the horizontal lines indicate $95 \% \mathrm{Cl}$; the area of the square is proportional to the size of the study sample in each centre. Adjustment within each centre was made for sex, smoking, parental education and centre. For the combined hazard ratio, the diamond indicates $95 \% \mathrm{Cl}$ from a model with centre as random effect; pheterogeneity $=0.367$. 


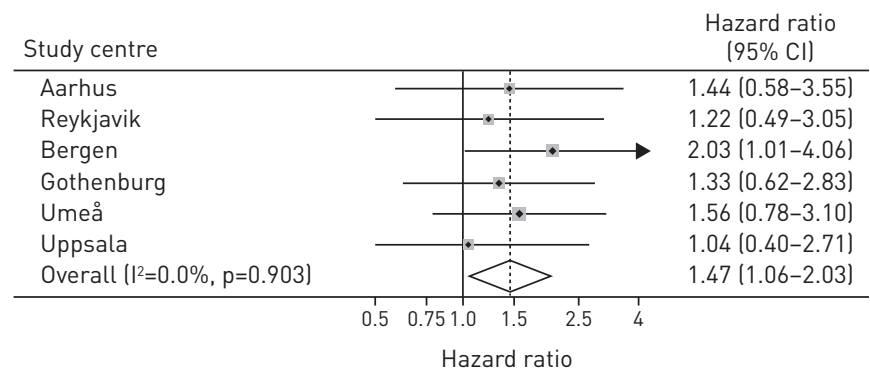

FIGURE 2 Hazard ratios for the association of welding with incident asthma by study centre in men. For each centre, the square gives the HR and the horizontal lines indicate $95 \% \mathrm{Cl}$; the area of the square is proportional to the size of the study sample in each centre. Adjustment within each centre made for smoking, parental education and centre. For the combined hazard ratio, the diamond indicates $95 \% \mathrm{Cl}$ from a model with centre as random effect; pheterogeneity $=0.896$. Tartu was excluded from the analysis.

A weakness of the survival analysis used in our study is the retrospective design counting on the participants recalling of when their respiratory symptoms started. However, such error would tend to attenuate findings, and not create the observed time-relationship between welding and airways disease. By choosing a starting age at 18 years we have been able to cover the total working period from the beginning of their working life for most participants as recommended in the study by RADON et al. [11]. The use of longitudinal data in the analysis strengthens the validity of our findings. There were only minor changes in the results when those with onset of rhinitis or asthma after 18 years of age, but prior to starting to weld instead of being excluded (as stated in the methods chapter) were included in the non-exposed group (data not shown).

In our study, few women had ever welded; the proportion of ever-welding was 10-times higher among men. In addition, as anticipated, the incidence of adult-onset asthma was almost two-times higher among women. As a result, since sex was associated both with the exposure (welding) and the health outcomes (asthma and to a lesser extent also rhinitis), it acted as a strong confounder in the association between welding and asthma. The small number of welding women with adult-onset asthma challenged the possibility of exploring potential effect modification of the welding effect by sex.

Those with parents with a lower education level were more prone to choose to be a welder, but we found no indications of childhood or adolescence asthma/rhinitis as negative selection factors for choosing an occupation involving welding. Lower incidence rates of both rhinitis and asthma in those with the longest duration of their exposure to welding fumes (welding $>8$ versus $\leqslant 8$ years) suggest that contracting rhinitis or asthma may lead to earlier retirement from welding activity.

Several studies have linked exposure to high molecular weight particles in the working environment to development of both IgE- and non-IgE mediated rhinitis and asthma, as in bakers [12, 13]. In low molecular weight exposure, the relation is less obvious. In nasal breathing, very few particles larger than $10 \mu \mathrm{m}$ penetrate further than the nose, but particles smaller than $2 \mu \mathrm{m}$ do not tend to become deposited

TABLE 3 Early life factors predicting work with welding

\begin{tabular}{lccc} 
& Never welding & Ever welding & Adjusted $^{\#}$ OR (95\% CI) \\
\hline Subjects n & 13630 & 2192 & \\
Childhood rhinitis $^{\text {I }}$ & $540(4.0)$ & $104(4.7)$ & $1.03(0.81-1.30)$ \\
Adolescence rhinitis $^{+}$ & $900(6.6)$ & $153(7.0)$ & $1.06(0.87-1.29)$ \\
Childhood asthma" $^{\text {Adolescence asthma }}{ }^{+}$ & $326(2.4)$ & $49(2.2)$ & $0.80(0.58-1.12)$ \\
Mother's university education $^{\S}$ & $223(1.6)$ & $32(1.5)$ & $1.00(0.66-1.50)$ \\
Father's university education $^{\S}$ & $1462(10.7)$ & $142(6.5)$ & $\mathbf{0 . 5 9}(\mathbf{0 . 4 7 - 0 . 7 4 )}$ \\
& $2322(17.0)$ & $240(10.9)$ & $\mathbf{0 . 7 0}(\mathbf{0 . 5 8 - 0 . 8 4 )}$
\end{tabular}

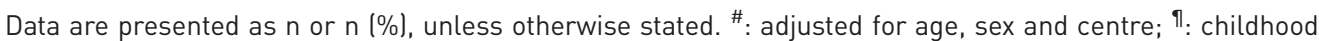
asthma/rhinitis is defined as asthma/rhinitis starting before 10 years of age; ${ }^{+}$: adolescence asthma/rhinitis is defined as asthma/rhinitis starting after 9 and before 18 years of age; ${ }^{\S}$ : number and percentage of those where mother/father have higher level of education (university level) versus lower and middle levels. Bold indicates values where the confidence intervals do not include 1.0, so these odds ratios may be considered statistically significant. 

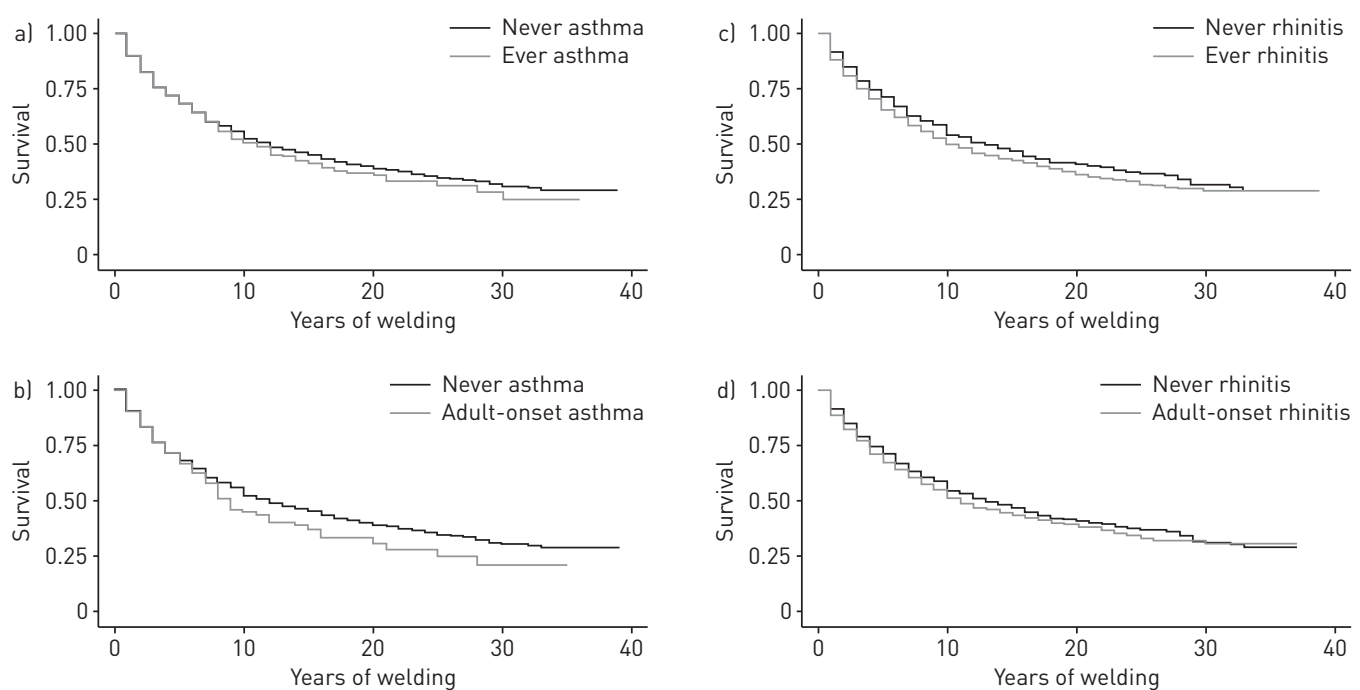

FIGURE 3 Kaplan-Meier survival estimates of welding by year of follow-up according to al asthma ever, b) adult-onset asthma, c) rhinitis ever, and d) adult-onset rhinitis.

in the nose. A characteristic aspect of the particles initially formed in the welding process is the small size, less than $0.5 \mu \mathrm{m}[14,15]$. They may therefore be anticipated for the most part to pass by the nasal mucosa, although LEONARD et al. [16] in a paper on stainless and mild steel welding stress that welding fumes consist of a wide range of complex metal oxide particles which may form large agglomerated chains of particles of different sizes, and thus can be deposited in all regions of the respiratory tract. In welding fumes there are also irritative gases of which some are very water soluble (goes to upper airways) and some less water soluble (goes more to lower airways), and this may also in part explain why we find indications of rhinitis development in this occupation with mainly low molecular weight exposure.

The incidence rate and hazard ratios for adult-onset asthma are higher in those welding $>25 \%$ of working time, and highest in those welding in stainless steel. The pathophysiological mechanism for asthma development when working in stainless steel is not known, but the higher content of chromium (15-30\%) and nickel (5-10\%), the generation of higher levels of oxygen radicals, and that these metals may deposit for a longer time in the lung tissue, are thought to be important factors, and in some cases it is found positive skin prick tests to these metals giving evidence for a possible IgE-mediated specific mechanism $[16,17]$. A differentiation in the incidence and hazard ratio was not seen with adult-onset rhinitis in our study and may signify other mechanisms in the upper airways than in the lower airways; probably non-specific irritative mechanisms.

We conclude that welding activity increased the risk for development of subsequent rhinitis and asthma (the latter, only among men). Our analyses suggested health-related selection out of welding activity; rhinitis appeared to promote quitting jobs involving welding. We did not find evidence of pre-employment selection; we could not find that adolescent asthma or rhinitis prevented subsequent work with welding. A causal association between welding and upper and lower airways disease seems plausible. The suggested findings should in particular raise the awareness of rhinitis in this occupation.

\section{References}

1 El-Zein M, Malo JL, Infante-Rivard C, et al. Incidence of probable occupational asthma and changes in airway calibre and responsiveness in apprentice welders. Eur Respir J 2003; 22: 513-518.

Meo SA, Al-Khlaiwi T. Health hazards of welding fumes. Saudi Med J 2003; 24: 1176-1182.

Antonini JM. Health effects of welding. Crit Rev Toxicol 2003; 33: 61-103.

Holm M, Kim JL, Lillienberg L, et al. Incidence and prevalence of chronic bronchitis: impact of smoking and welding. The RHINE study. Int J Tuberc Lung Dis 2012; 16: 553-557.

5 Lillienberg L, Zock JP, Kromhout $\mathrm{H}$, et al. A population-based study on welding exposures at work and respiratory symptoms. Ann Occup Hyg 2008; 52: 107-115.

6 Bakerly ND, Moore VC, Vellore AD, et al. Fifteen-year trends in occupational asthma: data from the Shield surveillance scheme. Occup Med (Lond) 2008; 58: 169-174.

7 Banga A, Reilly MJ, Rosenman KD. A study of characteristics of Michigan workers with work-related asthma exposed to welding. J Occup Environ Med 2011; 53: 415-419.

8 Hannu T, Piipari R, Tuppurainen M, et al. Occupational asthma caused by stainless steel welding fumes: a clinical study. Eur Respir J 2007; 29: 85-90. 
9 Hellgren J, Lillienberg L, Jarlstedt J, et al. Population-based study of non-infectious rhinitis in relation to occupational exposure, age, sex, and smoking. Am J Ind Med 2002; 42: 23-28.

10 Burney PG, Luczynska C, Chinn S, et al. The European Community Respiratory Health Survey. Eur Respir J 1994; 7: 954-960.

11 Radon K, Gerhardinger U, Schulze A, et al. Occupation and adult onset of rhinitis in the general population. Occup Environ Med 2008; 65: 38-43.

12 Nieuwenhuijsen MJ, Burdorf A. Three centuries of research on baker's asthma: how close are we to prevention? Ann Occup Hyg 2001; 45: 85-87.

13 Storaas T, Steinsvag SK, Florvaag E, et al. Occupational rhinitis: diagnostic criteria, relation to lower airway symptoms and IgE sensitization in bakery workers. Acta Otolaryngol 2005; 125: 1211-1217.

14 Brain JD, Valberg PA. Deposition of aerosol in the respiratory tract. Am Rev Respir Dis 1979; 120: 1325-1373.

15 Salvaggio JE. Inhaled particles and respiratory disease. J Allergy Clin Immunol 1994; 94: 304-309.

16 Leonard SS, Chen BT, Stone SG, et al. Comparison of stainless and mild steel welding fumes in generation of reactive oxygen species. Part Fibre Toxicol 2010; 7: 32.

17 Antonini JM, Taylor MD, Zimmer AT, et al. Pulmonary responses to welding fumes: role of metal constituents. J Toxicol Environ Health A 2004; 67: 233-249. 